
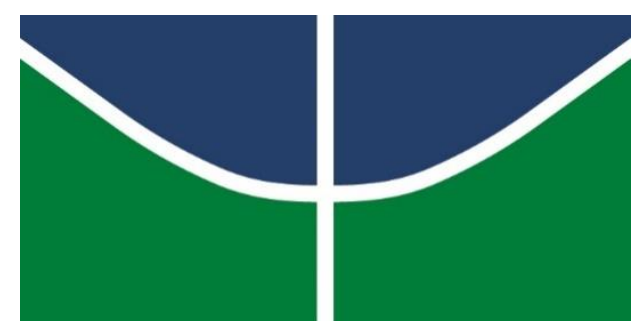

Universidade de Brasília

Faculdade de Comunicação

Comunicação Social - Comunicação Organizacional

\title{
Artigo
}

Gestão do Conhecimento e Comunicação Interna: uma análise de convergências para a melhoria da Comunicação Organizacional em instituições públicas

Autor: Jônathas Seixas de Oliveira

Orientadora: Profa. Dra. Liziane Guazina

Brasília, DF 


\section{Gestão do Conhecimento e Comunicação Interna: uma análise de convergências para a melhoria da comunicação organizacional em instituições públicas.}

\section{Jônathas Seixas de Oliveira ${ }^{1}$}

Resumo: Este artigo trata sobre as questões teóricas relativas a aplicabilidade do compartilhamento de conhecimento e estratégias oriundas da teoria de Gestão do Conhecimento em projetos de comunicação interna de órgãos públicos no Brasil, observando a experiência obtida no Conselho Nacional de Justiça. O objetivo é discutir a importância da relação do diálogo entre as teorias da Gestão do Conhecimento e da Comunicação Organizacional, especialmente no que diz respeito às suas discussões sobre cultura organizacional, planejamento e gestão da comunicação interna com o intuito de verificar as convergências e como as teorias se relacionam na prática comunicacional dos gestores de comunicação. A fluidez e a melhoria nos processos de comunicação interna entre os públicos que interagem nas organizações são alguns dos resultados observados com a realização de entrevistas e quadros comparativos ao longo do artigo.

Palavras-Chave: Conhecimento, Comunicação Interna, Gestão.

Abstract: This article deals with the theoretical questions related to the applicability of knowledge sharing and strategies derived from the theory of knowledge management in internal communication projects of public agencies in Brazil, observing the experience obtained in the National Council of Justice. The objective is to discuss the importance of the relationship of the dialogue between theories of Knowledge Management and Organizational Communication, especially with regard to their discussions on organizational culture, planning and management of internal communication in order to verify the convergences and how theories relate in the communicational practice of communication managers. The fluidity and improvement in the internal communication processes among the publics that interact in the organizations are some of the results observed with the accomplishment of interviews and comparative tables throughout the article.

Keywords: Knowledge, Internal Communication, Management

\footnotetext{
1 Jônathas Seixas de Oliveira, graduando em Comunicação Organizacional - Comunicação Social, matrícula 13/0029556, pela Faculdade de Comunicação da Universidade de Brasília, sob orientação da Prof. ${ }^{a}$ Dr. ${ }^{a}$ Liziane Guazina, da Faculdade de Comunicação da Universidade de Brasília.
} 


\section{Introdução e Contextualização}

A ideia de realização deste artigo nasceu no meio de um processo de criação de planejamento de comunicação interna do Conselho Nacional de Justiça em meados de fevereiro de 2017. O projeto visava abranger todas as pessoas da organização e fazer com que o conhecimento sobre o trabalho que é desenvolvido nas mais diversas seções e departamentos fosse disseminado por toda a instituição. Enquanto desenhava-se o escopo do projeto e buscava-se conhecimento teórico que justificasse a execução desse projeto, a teoria da Gestão do Conhecimento e as implicações práticas e objetivas que seus processos efetuam nas organizações cruzaram o caminho do processo de criação.

A dificuldade em encontrar outros órgãos que pudessem agregar à produção deste trabalho e promover comparações e pareamentos, fizeram com que a análise teórica e empírica do tema fosse o principal eixo na realização do artigo que começa com a introdução e contextualização do por que trabalhar este tema, além de estabelecer o Conselho Nacional de Justiça como local de fala e observação.

Para compreender a importância de gerir bem o conhecimento dentro das organizações (ANGELONI, 2008), para lidar com todos os seus públicos de forma a comunicar sempre de forma clara e eficaz, decidiu-se buscar alinhar o tema da Gestão do Conhecimento aplicado à execução e planejamento de projetos de comunicação interna por meio de uma análise teórica comparativa entre as teorias do Conhecimento e da Comunicação.

Discutir sobre a importância da Gestão do Conhecimento é uma necessidade latente no meio da Comunicação Organizacional identificada pelo lapso de conteúdo observado durante o breve levantamento de dados para a produção deste artigo e justifica-se pelo fato de que bons processos de comunicação ocorrem quando há conhecimento sobre os objetos em questão, divulgados por toda a instituição.

Neste artigo a teoria da Gestão do Conhecimento será abordada a partir da conceituação básica e por nivelamento de conteúdo, passando pela aplicação e desdobramentos da Gestão do Conhecimento nas organizações, alcançando de forma objetiva os projetos de comunicação interna e como sua relação deve ser observada na busca por excelência comunicacional com o objetivo de discutir a importância da relação do diálogo entre as teorias da Gestão do Conhecimento e da 
Comunicação Organizacional por meio de análise teórica, entrevistas, quadros comparativos e diálogo entre autores.

\section{Referencial Teórico}

A necessidade de diálogo com outros campos do saber que não apenas os relacionados à Comunicação Organizacional, faz-se necessária nessa delimitação de referencial teórico, tendo em vista a pluralidade de campos em que a Gestão do Conhecimento se aplica.

Autores como Angeloni (2008), Davenport \& Prusak (1999), Marchiori (2009), Duarte e Monteiro (2009) e Bueno (2009), dialogam sobre a Gestão do Conhecimento e conceitos de Cultura e Comunicação Organizacional que serão bastante utilizados neste artigo.

A autora Margarida Kunsch (2003, p. 150), uma das primeiras estudiosas da comunicação a utilizar o termo comunicação organizacional a define como

\footnotetext{
A disciplina que estuda como se processa o fenômeno comunicacional dentro das organizações no âmbito da sociedade global. Ela analisa o sistema, o funcionamento e o processo de comunicação entre a organização e seus diversos públicos.
}

A aplicabilidade da Gestão do Conhecimento e o compartilhamento do conhecimento se mostra propensa a acontecer de forma relacional com a cultura organizacional que se experimenta nas instituições. Algumas questões são importantes para assegurar essa aplicabilidade como explica Schein (1992, apud ANGELONI, 2008, p. 59): “a percepção de que a criação, a tolerância, e o respeito de variadas subculturas organizacionais possibilitariam gerar soluções aos mais diversos problemas", é uma dessas questões que, quando valorizadas, facilitam processos e geram maior apropriação tanto do que se quer disseminar dentro de uma organização quanto do que já existe e se pretende perpetuar. Essa consciência coletiva sobre o respeito às diversas realidades que uma organização experimenta é uma das principais a serem observadas.

Ignorar aquilo que já é real e presente na rotina das organizações é negligenciar e inutilizar processos que funcionam e poderiam ser aperfeiçoados para a melhor transmissão e gestão do conhecimento. Olhares atentos ao que ocorre no dia a dia das organizações são fundamentais para perceber fluxos, padrões, alterações de 
comportamento e quaisquer outras mudanças significativas na cultura de uma organização.

Entender as organizações como organismos vivos e relacionais alinha-se ao pensamento de Marchiori (2009) quando afirma que "[...] em resumo, a cultura é compartilhada, ressalta o comprometimento das pessoas com valores, tem sentido emocional, estabelece identificação dos membros e aprova ou não comportamentos. " (2009, apud ANGELONI, 2008, p. 297). Por essa razão,

[...] fica claro que o estudo da cultura é um processo que necessariamente envolve e produz conhecimento. O diálogo, nesse aspecto, é essencial e constrói os relacionamentos, gerando significados que podem ser transformados em conhecimento compartilhado, dependendo da realidade encontrada. (MARCHIORI, 2009, apud ANGELONI, 2008, p. 312).

Para que todo esse pensamento siga uma linha fluida no raciocínio, será trabalhada a conceituação sobre ideias basilares que sustentam a teoria da gestão do conhecimento. Em seguida, na análise das convergências observadas, conceitos como cultura organizacional e comunicação serão apresentados de forma a amparar a discussão sobre gestão do conhecimento aplicada à projetos de comunicação em órgãos públicos que virá a seguir, concluindo a análise.

\section{Notas Metodológicas}

A revisão bibliográfica, a observação direta como técnica de pesquisa e as entrevistas realizadas são as bases metodológicas deste trabalho.

Escolheu-se trabalhar sobre o tema por meio da observação in loco garantida pelo Conselho Nacional de Justiça (CNJ), enquanto o pesquisador autor deste artigo ainda era estagiário na Seção de Comunicação Institucional do CNJ. O CNJ é "uma instituição pública que visa aperfeiçoar o trabalho do sistema judiciário brasileiro, principalmente no que diz respeito ao controle e à transparência administrativa e processual" (Fonte: Portal CNJ na Internet) que, por meio de diversas ações busca beneficiar a sociedade brasileira trazendo celeridade, efetividade e decisões justas ao poder judiciário como um todo. A escolha pelo Conselho Nacional de Justiça deu-se por conta do espectro macro que o órgão ocupa no âmbito da esfera pública do poder judiciário no Brasil, trazendo a importante representatividade de outras instituições 
públicas. Toma-se o CNJ por exemplo daquilo que acontece em outros locais, mas não como regra rígida e única.

Tendo bases para o início da jornada, partiu-se para o levantamento bibliográfico que somasse ao artigo peso teórico, conferindo além de credibilidade, autoridade sobre o tema a ser tratado. Fazer uma correlação de tudo o que foi levantado bibliograficamente ao principal assunto do artigo foi uma fase importante que balizou o desenho primário deste trabalho.

Analisar e compreender os pontos de convergências entre as teorias de Gestão do Conhecimento e Comunicação foi um passo seguinte que gerou o desenvolvimento de parte da análise deste artigo. Em seguida, a busca por fontes que fornecessem um tom prático a tudo o que até então se discutia de forma puramente teórica foi um passo importante. Dessa busca surgiram duas entrevistas com pessoas experientes tanto em gestão do conhecimento quanto em comunicação interna que agregaram ao artigo teórico um pouco de empirismo necessário para uma visão ampla e receptiva a conceitos em constante mudança e aprimoramentos.

A partir dos dados coletados, das informações assimiladas e das conversas e leituras pôde-se desenvolver quadros comparativos e analíticos que cruzam pontos de convergência entre as duas áreas de que o artigo trata: Gestão do Conhecimento e Comunicação Interna.

Compreender que é possível estabelecer relação teórica entre dois campos que não necessariamente caminham sempre juntos fez parte do processo de descoberta e produção de conhecimento.

A referenciação teórica proposta logo antes destas notas metodológicas, projeta as bases do percurso de análise que virão em seguida a este tópico. A inclusão de entrevistas e depoimentos de profissionais da área agregam à análise um pouco do empirismo do processo que discute a aplicabilidade do tema, assim como a demonstração de quadros informativos e que mostram a relevância das semelhanças entre Gestão do Conhecimento e Comunicação Interna.

Para encerrar, por ora, a análise sobre o tema, algumas considerações finais que se fazem pertinentes à conclusão da discussão foram incluídas, seguidas da bibliografia utilizada em todo o processo de realização do artigo. $O$ anexo 1 deste trabalho nada mais é do que o roteiro de entrevista estabelecido para nortear as conversas e encontros com ambas as entrevistadas. Alterações mínimas e apenas de 
adequação de linguagem aconteceram durante as conversas realizadas de maneira verbal com as profissionais entrevistadas. 


\section{Análise de Convergências}

O início de um novo processo só pode acontecer com a visão ampliada sobre todo o percurso a ser percorrido, o que estabelece uma solidez sobre aquilo que se deseja desenvolver ou evoluir. Esta visão ampliada é garantida quando há limites que contornam e definem aquilo que será desenvolvido.

Como mencionado na introdução deste trabalho, a inspiração para a realização do mesmo deu-se por meio da observação in loco no Conselho Nacional de Justiça. Enquanto estagiário da Seção de Comunicação Institucional, parte da Secretaria de Comunicação Social do Conselho, o autor teve a oportunidade de vivenciar a experiência do fazer comunicação organizacional de forma prática e diária. A comunicação interna do órgão, detentora de meios como Intranet e E-mail Institucional, além de uma equipe com profissionais do jornalismo, design e comunicação organizacional realiza diversos trabalhos de divulgação e em parceria inclusive com outros setores da organização.

Diante da rotina estabelecida e de forma a manter um fluxo de novas informações constante sendo veiculados pelos canais disponíveis ao órgão, observouse a necessidade de trabalhar de forma mais incisiva, mas sutil, junto aos outros setores da organização ainda não participantes desse fluxo constante de troca de informações e conhecimento. Para tal, diversas opções foram levantas e chegaram a ser aplicadas algumas técnicas obtidas de forma despretensiosa no decorrer da prática profissional de outras tarefas, na busca de se encontrar a forma ideal de se obter conhecimento que pudesse ser compartilhado dentro do Conselho Nacional de Justiça, o que se apelidou como ronda institucional².

Enquanto observando e vivenciando outros momentos da organização e envolvido na produção diária de conteúdo noticiável e de interesse do público interno, houve a realização de um encontro de líderes e gestores de todas as áreas do CNJ e em uma das discussões levantou diversas vezes a necessidade de o compartilhamento de conhecimento fluir de forma mais natural dentro do órgão. Muitas tarefas eram feitas de forma similar, ou até mesmo retrabalhos, o que impedia a produtividade e o avanço em diversos aspectos organizacionais.

\footnotetext{
2 "Ronda Institucional" foi a forma como o projeto de busca de informações que pudessem ser compartilhadas dentro do Conselho Nacional de Justiça foi apelidado.
} 
O desconhecimento compartilhado era causador de transtornos ou simplesmente barreiras impostas para melhorias e conclusão de diversos projetos, o que obviamente é bastante maléfico não só para a organização de forma geral, como para aspectos como a cultura e o clima organizacional que, prejudicados pela falta de motivação e entusiasmo de seus colaboradores, fazia pesar sobre os ombros principalmente dos gestores, a incumbência de administrar pessoas enfadadas por processos repetitivos e desmotivadores.

Nesse cenário nasceu a ideia, por meio da equipe da Seção de Comunicação Institucional, de ressuscitar o projeto da "ronda institucional", mas aplicando conceitos adquiridos por meio de pesquisa e insights obtidos pela mediadora do encontro de gestores e líderes mencionado anteriormente. Como gerir bem o conhecimento era o desafio e aplicar os conceitos dessa teoria ao projeto de comunicação interna que visava promover maior integração e compartilhamento de conhecimento, ideias, práticas, expertises e outros, a missão.

Um aspecto que ficou bastante claro era que não se podia mais perder tempo ao aplicar uma metodologia que impusesse mais uma obrigação sobre os gestores e todo o corpo de colaboradores da instituição.

Por essa razão, a essência do projeto vislumbrava uma dinâmica mais natural, menos impositiva e que soasse bem diante do público interno de gestores. A ideia de propor a gestão do conhecimento de modo que os gestores da organização quisessem compartilhar projetos, ações e qualquer outra forma de conhecimento era o caminho, que é o que a Comunicação Organizacional propõe.

Por esse motivo, cabe abordar aspectos fundamentais próprios do universo da Comunicação Organizacional que, se pouco observados, influenciam de forma negativa no processo de análise de similaridades e aplicáveis da Gestão do Conhecimento à comunicação interna das organizações.

Os gestores de comunicação, talvez mais do que os gestores das demais áreas das organizações são aqueles que precisam estar atentos às transformações, processos, realidade, contexto e especificidades a que as organizações estão submetidas. A correta percepção sobre o ambiente em que se desenvolvem todas as ações aqui discutidas é fundamental e imprescindível para que não se cometam erros ou direcionamentos equivocados. 


\begin{abstract}
A comunicação de excelência, nos tempos modernos, está umbilicalmente associada ao exercício da cidadania, à gestão da responsabilidade social, ao respeito à diversidade e à valorização profissional e pessoal. Como sistemas abertos, portanto em interação permanente com o meio ambiente (a comunidade, o mercado, a sociedade em geral), as organizações devem cultivar o diálogo, a transparência e a relação saudável com todos os seus públicos de interesse. A convivência exige aproximação, não distanciamento; exige diálogo, não afirmação de autoridade. (BUENO, 2009, apud KUNSCH, 2009, p. 384)
\end{abstract}

Não basta apenas ser sensível aos ambientes internos e externos. Percebê-los apenas não é suficiente. A passividade habita entre aqueles que apenas estão atentos, é necessário agir com pró atividade em relação à realidade observada, respeitando as peculiaridades do meio em que se trabalha e adequando o modo de agir de acordo com o que surge adiante do gestor responsável.

Comunicar de forma clara é essencial; e como ponderam Duarte e Monteiro (2009, apud KUNSCH, 2009, p.336), "comunicar sobre comunicação é, portanto, o grande desafio. " Fazer-se entender com simplicidade, objetividade e dinamismo não é uma tarefa fácil, mas se aplicada com as técnicas corretas no momento ideal gera resultados satisfatórios. Esse processo de comunicação é importante de ser relacionado à essência do que é comunicação:

Talvez seja possível pensar que os avanços serão significativos quando tornarmos a comunicação um desafio de toda a organização, dos dirigentes ao mais novo contratado, bem como quando ela for encarada em sua acepção original: communicare, tornar comum, ou seja, viabilizar o diálogo e a interação, facilitar o acesso, a compreensão, a participação, o reconhecimento e a atenção ao outro. (DUARTE; MONTEIRO, 2009, apud KUNSCH, 2009, p. 336)

Em meio ao processo de "tornar comum", a identificação daquilo que é essencial que se difunda pela organização é fundamental. Um conceito tal como valornotícia oriundo do jornalismo é aplicável a esse momento na vida de um gestor de comunicação. Ele precisa fazer o papel de um editor nas redações jornalísticas, avaliando a eficácia daquilo a ser comunicado e replicado dentro das organizações. Ser mero reprodutor daquilo que chega às mãos não é gestão, mas sim trabalho mecânico e irracional que configura irresponsabilidade por parte do gestor. 
A "capacidade de pensar estrategicamente, de ser múltiplo, dominar as plataformas digitais e gerir recursos de toda ordem" (QUIROGA, GUAZINA e DEL BIANCO. 2014, apud FORMIGA, 2014, p. 57) é qualificada como resultado das demandas apresentadas pelo mundo em constantes transformações em que vivemos e aplicador de pressões transformadoras também no mercado de trabalho que envolve organizações públicas, privadas e do terceiro setor. Essa capacidade é requerida dos gestores de comunicação e faz parte da vocação daqueles que estudam e decidem praticar a comunicação organizacional.

Defender um ambiente democrático que valorize a presença individual de cada integrante da organização, conscientizando sobre a necessidade de se fazer parte do grupo para que haja força na organização, é chave para abertura de portas no rumo do progresso e avanços significativos na qualidade do ambiente em que se exercitam as funções laborais com propósitos comuns. O alinhamento orgânico dos objetivos, metas, missão, visão e valores das instituições, sejam de quais naturezas forem, é importante para que o discurso seja único e fluido, sem ruídos ou peças dissonantes da composição consolidada.

Nessa linha de defesa pelo ambiente promotor de uma cultura organizacional saudável, Duarte e Monteiro (2009, apud KUNSCH, 2009, p.341) argumentam o que é necessário para fazer uma comunicação eficaz:

Para fazer a comunicação organizacional fluir, é preciso criar uma consciência comunicativa. $E$ isso só é possível a partir de uma cultura organizacional em que prevaleçam um ambiente de transparência, confiança e o estímulo à cooperação. Redistribuir a informação, fazê-la circular nos mais diversos sentidos e nos mais diversos espaços é ampliar a participação, o engajamento, a qualidade da gestão e a capacidade de ação nas organizações. Assim, a comunicação pode gerar maior cooperação entre os integrantes da organização. (DUARTE; MONTEIRO, 2009, apud KUNSCH, 2009, p. 341)

Sendo assim, para que essa comunicação seja eficaz e para tratar sobre gestão e compartilhamento de conhecimento é necessário que se ponha de forma clara aquilo que é e aquilo não é conhecimento. Termos como dados, informações, mensagens, referências, conceitos e outros figuram no ambiente que circunda o conhecimento e precisam ser esclarecidos para que não haja confusões.

Dados, segundo Davenport e Prusak (1999, p.2), "são um conjunto de fatos distintos e objetivos, relativos a eventos. (...) Dados não fornecem julgamento nem 
interpretação e nem qualquer base sustentável para a tomada de decisão", e podem inclusive fazer parte do processo de formação do conhecimento, mas por si só não pode ser considerado conhecimento.

Assim como os dados, as informações, conjunto de dados trabalhados e alinhados de forma mais organizada e compilada, também não configuram conhecimento. Davenport e Prusak (1999, p. 4) consideram que

[...] a informação tem por finalidade mudar o modo como o destinatário vê algo, exercer algum impacto sobre seu julgamento e comportamento. Ela deve informar; são os dados que fazem a diferença. O significado original da palavra "informar" é "dar forma a", sendo que a informação visa a modelar a pessoa que a recebe no sentido de fazer alguma diferença em sua perspectiva ou insight.

Por essa razão, a delimitação de fronteiras é tão importante. Termos parecidos e comumente tratados como iguais ou semelhantes possuem significados distintos que se não esclarecidos podem e gerarão dificuldades no processo de implementação e aplicação da Gestão do Conhecimento a projetos de comunicação interna.

Ambos os conceitos constituem para as organizações um conjunto de aspectos valiosos que possuem valor estratégico. A boa gestão e correta aplicação de esforços a fim de decodificar e agregar significado a esses conceitos chave pode garantir o sucesso para geração de conhecimento qualificado e compartilhável. Conhecimento válido é aquele que pode ser transmitido de forma fluida e descomplicada, ainda que para que isso aconteça um esforço intelectual de grande porte, além de investimentos com recursos financeiros e outros tipos sejam aplicados ao processo de compartilhamento.

O conhecimento que tratamos aqui tem o significado de estar convencido de, distinguir e ver. E é interessante observar essa conceituação do termo porque a intenção é justamente essa: promover o entendimento de que conhecer algo possibilita à parte conhecedora enxergar as coisas de modo diferente, ter discernimento sobre aquilo que se observa se forma clara. Saber o que fazer durante os processos, como gerenciá-los, como trabalhar seus caminhos e orientar de forma objetiva as metas que se desejam alcançar, tornando todas essas possibilidades plausíveis àquele detentor do conhecimento.

Para além da conceituação apresentada anteriormente, Davenport e Prusak (1999, p. 6), já mencionados neste artigo, apresentam a noção de que o conhecimento "é uma mistura fluida de experiência condensada, valores, informação contextual e 
insight experimentado, a qual proporciona uma estrutura para a avaliação e incorporação de novas experiências e informações. "

O conhecimento pode e, na maioria das vezes, não está somente embutido ou acumulado em pessoas. Ele também transita por outros canais difusores e detentores tais como documentos, relatórios, publicações oficiais e uma infinidade de outros meios que pode ser observada nos fluxos laborais de uma organização. A diferença na localização do conhecimento é definida de forma a gerar dois grupos de conhecimento: o tácito e o explícito (ANGELONI, 2008).

O conhecimento tácito é aquele que transita e habita as esferas conjunturais dos seres humanos. Os integrantes da organização por experiência, ensinamentos e deduções lógicas frutos do raciocínio possuem esse tipo de conhecimento que já foi incorporado às suas redes mentais de armazenamento e compreensão. $O$ conhecimento explícito, por sua vez é aquele encontrado e "embutido em produtos, processos, serviços e ferramentas, ou registrado em documentos" (ANGELONI, 2008, p. 170).

Vale aqui também apresentar de forma breve a "Espiral do Conhecimento" dos autores Hirotaka Takeuchi e Ikujiro Nonaka, desenvolvida de forma a apresentar os ciclos de transformação do conhecimento. A imagem autoexplicativa a seguir apresenta estes ciclos.

\section{Figura 1: Espiral do Conhecimento}

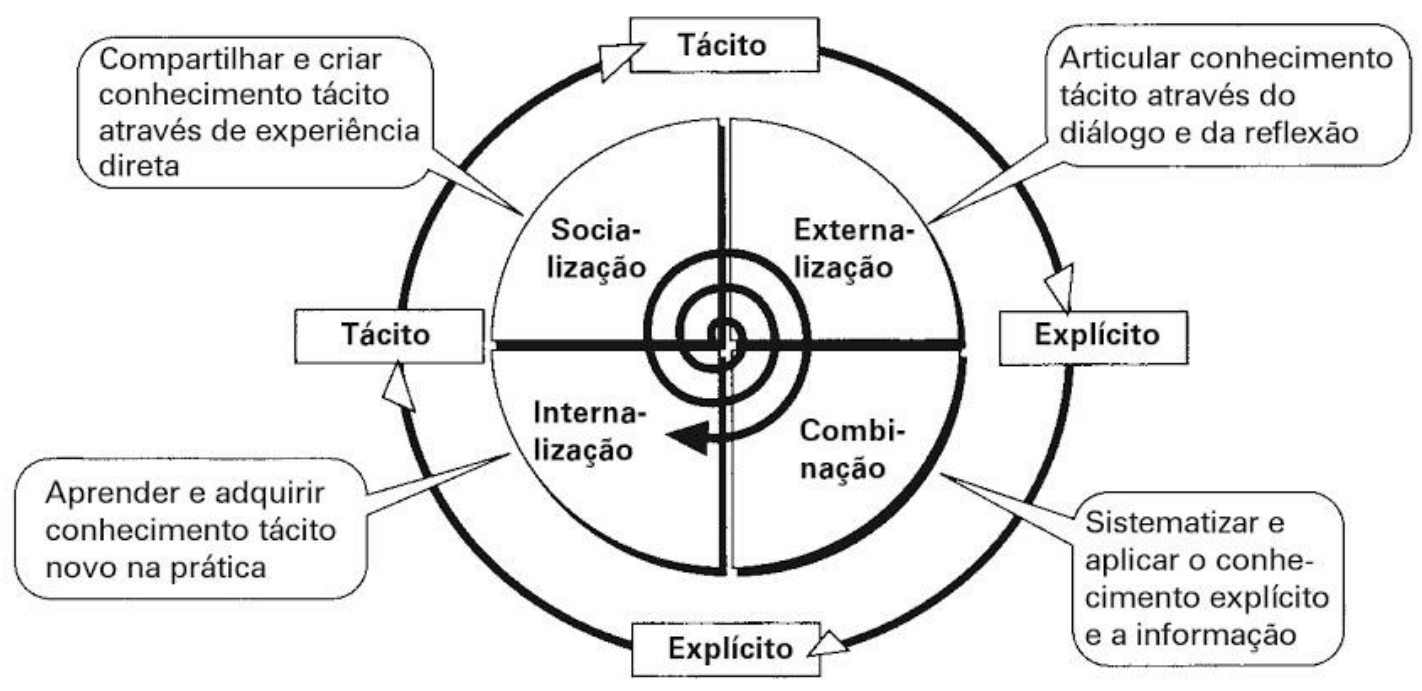

Fonte: Adaptada de Nonaka e Takeuchi, 1995. Takeuchi, apud TAKEUCHI; NONAKA, 2008, p.24. 
Definidos de forma sucinta, os termos essenciais a essa análise, observando de forma atenta e minuciosa todas as particularidades concernentes ao universo da Ciência da Informação, gestão e linguagem, próprios do ambiente que circunda o saber de forma geral, obtêm-se chancela para avançar no processo de análise sobre as convergências e a aplicação na prática da multiplicação compartilhada do conhecimento nas organizações, trabalhando de forma específica nos projetos de comunicação interna das organizações públicas. Antes, contudo, apresenta-se um quadro como primeira análise dos pontos de convergência, em que cada ferramenta própria do universo da comunicação interna encontra relação direta com o tipo de conhecimento que essa ferramenta melhor pode transmitir.

Quadro 1: Ferramentas de comunicação interna e direta associação aos tipos de conhecimento melhor conduzido por elas.

\begin{tabular}{|l|c|c|}
\hline \multicolumn{1}{|c|}{$\begin{array}{c}\text { Ferramentas } \\
\text { de Comunicação }\end{array}$} & $\begin{array}{c}\text { Conhecimento } \\
\text { Tácito }\end{array}$ & $\begin{array}{c}\text { Conhecimento } \\
\text { Explícito }\end{array}$ \\
\hline Notícias & $\mathbf{X}$ & $\mathbf{X}$ \\
\hline Briefing & $\mathbf{X}$ & $\mathbf{X}$ \\
\hline Planos de Comunicação & $\mathbf{X}$ & \\
\hline $\begin{array}{l}\text { Reuniões de Pauta/Alinhamento } \\
\text { de Conteúdo }\end{array}$ & $\mathbf{X}$ & $\mathbf{X}$ \\
\hline Pesquisas de Satisfação & & $\mathbf{X}$ \\
\hline Material Gráfico Visual & $\mathbf{X}$ & $\mathbf{X}$ \\
\hline Gerenciamento de Mídias Sociais & $\mathbf{X}$ & $\mathbf{X}$ \\
\hline Atendimento à Imprensa & $\mathbf{X}$ & $\mathbf{X}$ \\
\hline Relações Públicas & & \\
\hline Campanhas Publicitárias & & \\
\hline Ações de Engajamento & & \\
\hline
\end{tabular}

Fonte: Elaboração própria.

Perceber no quadro acima que cada ferramenta de comunicação possui uma habilidade e um alcance diferenciados, no que tange a distribuição e a difusão do conhecimento tácito e do conhecimento explícito é importante para que erros sejam evitados durante a gestão de projetos e rotinas da comunicação organizacional que sempre clama para si atenção e diligência de seus gestores responsáveis. 
O trabalho de decodificação e transformação dos dados e informações obtidos é privilégio da mente humana que experimentada e, a depender da orientação que recebe, os traduz de forma a conceber conhecimento tácito ou explícito que, segundo Angeloni (2008), cada um possui um caminho de maior afinidade para sua divulgação:

São dois os modos de compartilhamento de conhecimento: por meio da informação e da tradição. Pela informação, o conhecimento é compartilhado de forma indireta (palestras, apresentações audiovisuais, manuais, livros). Pela tradição, o conhecimento é compartilhado de forma direta, ou seja, o receptor participa do processo de transferência (acontece de indivíduo para indivíduo por meio do aprendizado pela prática). [...] A informação é favorável ao compartilhamento de conhecimentos explícitos, enquanto a tradição deve ser utilizada no compartilhamento de conhecimentos tácitos. (ANGELONI, 2008, p.173-174).

A disseminação de conhecimento precisa ocorrer de forma a alcançar o máximo de pessoas possíveis e que seja o mais nivelado possível para que não ocorram atritos e dissonâncias durante processos de planejamento e execução de ações na organização. A clareza, objetividade e a fluidez são essenciais e estão postas de forma clara, acima.

Sobre a importância da Gestão do Conhecimento nas organizações públicas, Laura Maciel, analista em gestão de pessoas no Supremo Tribunal Federal (STF), responsável pelo programa de multiplicadores de conhecimento da Seção de Programas Institucionais do STF afirmou em entrevista exclusiva que

Gestão do Conhecimento é algo muito necessário em todas as organizações, não só nas públicas, porque toda organização possui o que é chamado de conhecimento tácito, que engloba todas as experiências dos colaboradores, do know-how das pessoas que trabalham na organização. Ocorre que esse conhecimento é de suma importância porque nele estão contidos, por exemplo, os processos de trabalho, tudo o que a pessoa sabe em relação ao trabalho dela. As ideias, as melhorias implementadas de modo informal. $\mathrm{E}$ quando nós não fazemos a gestão deste para que o conhecimento tácito se torne explícito, a organização perde muito.

\section{Ela ainda acrescenta que}

[...] quando a gente incentiva a Gestão do Conhecimento nas organizações seja na administração pública ou na iniciativa privada, são criadas oportunidades para que o conhecimento tácito se torne explícito e ajude na melhoria dos resultados organizacionais. As melhorias ocorrem por diversas razões. A mais óbvia é porque nós conseguimos resgatar todo o conhecimento que ainda não foi formalizado nas organizações para buscar 
melhoria contínua dessa organização que aprende. Lembro de Peter Senge (1990) que falava muito dessa necessidade de criarmos organizações que aprendem. Mas talvez um dos maiores ganhos que uma organização consegue com a Gestão do Conhecimento seja mesmo o ganho da valorização do capital humano da instituição.

Esse ganho é comprovado por diversos autores (KUNSCH, 2009. ANGELONI, 2008) que trabalham a conceituação e aplicação da gestão e o compartilhamento de conhecimento nas organizações. Alguns elementos favorecem a Gestão do Conhecimento e estão diretamente relacionados ao capital humano das organizações. Um deles é o que Schein (1992, apud ANGELONI, 2008, p. 60) apresenta que é o de se "ter como pressuposto o fato de as pessoas serem capazes de entender e modificar o ambiente pela sua atuação. A atitude esperada dos membros da organização seria a de fazer frente às questões que se apresentarem, de agirem procurando eliminar a resignação. "

Laura (2017) também complementa que "quando nós estimulamos as pessoas a repassarem seus conhecimentos, nós estamos na verdade criando formas de motivá-las a se sentirem construtores de uma organização de qualidade. "

$\mathrm{Na}$ relação direta com a comunicação interna que atua como articuladora de processos envolvendo muitas informações e conhecimentos dentro da organização, a Gestão do Conhecimento é essencial.

Considerando que a comunicação interna é responsável por disponibilizar as informações e o conhecimento de forma vertical e horizontal dentro da instituição, comunicação interna e Gestão do Conhecimento tem tudo a ver. Porque é inerente à Gestão do Conhecimento questionamentos como: quais são as informações relevantes dentro da instituição que devem ser resgatadas, repassadas, processadas por todos os colaboradores? E quando a gente faz esses questionamentos das informações relevantes para melhoria dos processos de trabalho e do andamento da instituição, é a comunicação interna que tem essa responsabilidade de repassar todas essas informações também. (MACIEL, 2017)

A proximidade de toda essa questão com o plano de fundo que a cultura organizacional integra nas organizações é perceptível e a associação do conceito de cultura organizacional à Comunicação Organizacional não pode ser ignorado.

Entre as descobertas teóricas da pesquisa bibliográfica realizada, alguns autores trazem, no interior de suas definições de cultura organizacional, a relação direta com a comunicação. Pepper (1995, p.36) afirma: "a comunicação cria a organização por meio da construção de 
culturas". Pacanowsky e O'Donnell-Trujillo (1982, p. 146) entendem que a organização é um todo: "cultura organizacional não é mais uma outra peça do quebra-cabeça, ela é o quebra-cabeça. Do nosso ponto de vista, a cultura não é algo que a organização possui; uma cultura é algo que uma organização é". (MARCHIORI, 2009, apud ANGELONI, 2008, p. 303)

Difundir de forma a transformar a cultura organizacional é algo orgânico e natural quando toda a plenitude de compreensão sobre a gestão do conhecimento forma multiplicadores motivados do conhecimento que receberam das mais diversas formas e não somente da organização presente, como de experiências adquiridas no passado nos âmbitos profissional e pessoal.

A necessidade de existência dos multiplicadores de conhecimento nas organizações é imprescindível, como complementou Laura (2017) ao dizer que

Hoje a gente tem visto que é um crescente nas instituições o investimento na formação de multiplicadores de conhecimento, só que não basta trazer apenas aspectos técnicos para essa formação de multiplicadores de conhecimento, é preciso, principalmente dentro da administração pública, linkar a formação desses multiplicadores com os valores que são inerentes à administração pública, que é o servir a sociedade, a construção de um legado servindo a sociedade.

Para além de todas as questões estratégicas e progressistas que a Gestão do Conhecimento possui e se aplicam dessa forma não só a projetos de comunicação de órgãos públicos, mas a toda a gestão dos diversos setores dessas organizações, a Gestão do Conhecimento encontra amparo também legal quando da exposição dos princípios que regem a administração pública no artigo nํ 37 da Constituição brasileira. Dentre os princípios de legalidade, impessoalidade, moralidade, publicidade e eficiência, a Gestão do Conhecimento situa-se mais proximamente especialmente aos princípios de moralidade, publicidade e eficiência.

Moralidade pela consciência correta de que o público deve permanecer sendo público de forma a colaborar com toda a sociedade. Publicidade, muito relacionado ao princípio de moralidade e claramente promovendo a difusão de todo o conhecimento adquirido por tradição e informação. E finalmente, mas não menos importante, pelo princípio da eficiência. Fazer mais com menos, propiciando um ambiente sustentável e descomplicado no que se refere à boa gestão de recursos das mais diferentes espécies.

Manter de forma clara sempre em mente a vocação do serviço público é elementar para aplicar a gestão e o compartilhamento do conhecimento a todos os 
processos da administração pública, e a especialista Laura Maciel (2017) ainda acrescenta que "obter bons resultados advindos dessa gestão do conhecimento, dessa melhoria de processos, consequentemente vai trazer os melhores resultados para a sociedade. E o serviço público está aí para isso."

Para além do que já foi exposto, um fator de extrema relevância se faz presente, que é a crise no setor público que o Brasil tem experimentado já há algum tempo. $\mathrm{A}$ busca por inovação e maneiras sustentáveis de gerir a máquina pública não são apenas aceitáveis e esperadas, como também urgentes.

Preservar uma administração inchada e repleta de processos desnecessários pode gerar retrocessos e inúmeros casos de retrabalho, inadmissíveis em uma realidade de recursos econômicos, políticos e administrativos escassos. Gerir o conhecimento, portanto, se apresenta não apenas como uma alternativa promotora de celeridade e eficiência, como também um caminho de relativa facilidade diante de todo um cenário com entraves e barreiras burocráticas impostas diuturnamente.

Em um ambiente onde a flutuação de colaboradores é relativamente alta devido a moções, cessões e transferências de funcionários de um órgão para outro, e ainda com o agravante político nesse processo que impõe grandes mudanças de equipes em períodos de novas gestões, o processo de Gestão do Conhecimento oferece também uma útil ferramenta que sustenta esses momentos de transição, garantindo a continuidade de ações que poderiam estar sendo desenvolvidas e nada interferem no modo como a nova gestão recém-chegada administra processos, mas conferindo consistência e solidez necessários ao bom desenvolvimento de qualquer iniciativa que vise a eficácia da máquina pública.

A maioria dos órgãos públicos no Brasil possui em seus objetivos estratégicos, diretrizes administrativas, metas, enfim, a finalidade de cumprir com os princípios estabelecidos na constituição já mencionados aqui neste artigo, e a prática da Gestão do Conhecimento certamente colabora como ferramenta para o alcance de todos os esses objetivos.

O planejamento, a discussão, o processo contínuo de aprendizado, a análise de riscos e a proposta de caminhos alternativos às obstruções nas estratégias delimitadas pelos gestores de uma organização devem ser fatores constantes e vivos sempre que do estabelecimento de fluxos organizacionais contínuos que se desejem ser duradouros e permanentes. 
A gestora da Seção de Comunicação Institucional do Conselho Nacional de Justiça, a analista judiciária Rejane Neves (2017) também avaliou em entrevista exclusiva para a realização desta análise que a Gestão do Conhecimento possui valor estratégico nos projetos de comunicação interna.

O compartilhamento de conhecimento é um gargalo no Setor Público. Por dentro das organizações tem-se uma noção errônea de que a posse de informações garante o poder e o status já que as muitas possibilidades de reconhecimento profissional, que se encontram com abundância na iniciativa privada, são mais escassas no âmbito público.

Apesar disso, a gestora avalia que

[...] a Gestão do Conhecimento pode otimizar as atividades desenvolvidas em uma instituição pública. A troca de conhecimento e informação estimula a criação; Da continuidade a projetos de forma multidisciplinar; evita retrabalhos; engaja os servidores, já que passam a perceber sua atividade como algo maior, que transpõe as barreiras do seu setor, da sua "baia". A organização se torna uma grande equipe, trabalhando em prol de um objetivo comum, a partir de diversos projetos colaborativos, que passam a ter relação entre si.

Sobre a aplicabilidade da Gestão do Conhecimento à comunicação interna de organizações, Rejane (2017) ponderou que a

[...] comunicação interna tem papel essencial nesse cenário, já que divulgará as ações, aproximará os atores, estimulará os relacionamentos e informará as áreas dos diversos projetos da instituição. Enfim, será a ponte e instrumento para que o compartilhamento de conhecimento ocorra. Em contrapartida, a Gestão do Conhecimento contribui com os projetos de endomarketing já que as ações se mostram muito mais eficientes quando se fala para um só público que está engajado e homogêneo e se identifica com os diversos temas explorados, independentemente se diz respeito à especialidade de sua área de atuação ou não, contanto que colabore para o alcance daquele objetivo comum, ou da instituição; o bem-estar do públicoalvo, o cidadão.

Cientes da profundidade e importância da boa estão de conhecimento dentro das organizações, assinalam-se em que as práticas naturais da área de Comunicação compartilham no modo de realizar com a Gestão do Conhecimento. O quadro a seguir visa esclarecer como ambas as vertentes caminham juntas e cooperam para o bom trabalho dos gestores de comunicação que, muito mais do que meros reprodutores de informações, são canais de transformação, análise e avaliação de conteúdo e 
conhecimento que, imbuídos de responsabilidade e peso estratégico, têm o poder de gerar grandes melhorias e avanços nas organizações.

Quadro 2: Relação entre as especificidades da Gestão do Conhecimento a as práticas de Comunicação Interna

\begin{tabular}{|c|c|c|}
\hline $\begin{array}{c}\text { Ferramentas } \\
\text { de Comunicação }\end{array}$ & $\begin{array}{c}\text { Gestão do } \\
\text { Conhecimento }\end{array}$ & $\begin{array}{c}\text { Comunicação } \\
\text { Interna }\end{array}$ \\
\hline Notícias & $\mathbf{X}$ & $\mathbf{X}$ \\
\hline Briefing & & $\mathbf{X}$ \\
\hline Planos de Comunicação & $\mathbf{X}$ & $\mathbf{X}$ \\
\hline $\begin{array}{l}\text { Reuniões de Pauta/Alinhamento } \\
\text { de Conteúdo }\end{array}$ & $\mathbf{X}$ & $\mathbf{X}$ \\
\hline Pesquisas de Satisfação & $\mathbf{X}$ & $\mathbf{X}$ \\
\hline Análise de Resultados & $\mathbf{X}$ & \\
\hline Material Gráfico Visual & $\mathbf{X}$ & $\mathbf{X}$ \\
\hline Gerenciamento de Mídias Sociais & $\mathbf{X}$ & $\mathbf{X}$ \\
\hline Atendimento à Imprensa & & $\mathbf{X}$ \\
\hline Relações Públicas & $\mathbf{X}$ & $\mathbf{X}$ \\
\hline Campanhas Publicitárias & $\mathbf{X}$ & $\mathbf{X}$ \\
\hline Ações de Engajamento & $\mathbf{X}$ & $\mathbf{X}$ \\
\hline Reuniões de Planejamento & $\mathbf{X}$ & $\mathbf{X}$ \\
\hline
\end{tabular}

Fonte: Elaboração própria.

Com a observação do quadro acima, pode-se perceber que a relação direta da Gestão do Conhecimento e a Comunicação interna existe em várias ferramentas de comunicação, já velhas conhecidas dos profissionais da área. Apenas um olhar mais analítico sobre o panorama exposto é suficiente para, além de identificar as similaridades dos temas, aplicar um ao outro visando uma melhor gestão e a boa prática da comunicação organizacional.

Somente três ferramentas tradicionais da comunicação apresentadas no quadro acima são apontadas como não possuindo relação direta entre as duas áreas de conhecimento: Gestão do Conhecimento e Comunicação Interna. Esse fato pode levar a reflexão do quanto a aplicação de uma área à outra é valiosa e proveitosa para 
a melhoria de processos de comunicação interna nas instituições públicas, que é justamente o que este trabalho propõe.

A título de exemplo, pode-se destacar a ferramenta "Reuniões de Pauta e Alinhamento de Conteúdo", que em seu processo de desenvolvimento trabalha diretamente com transmissão de conhecimento prático (do tácito para o explícito) quando no momento de tomadas de decisões sobre o que será comunicado ou não, ao mesmo tempo em que esse mesmo processo decisório define o conteúdo a ser abordado pelos comunicadores envolvidos. Conhecimento e Comunicação caminhando juntos no desenvolver de uma mesma ferramenta de comunicação.

Mesmo as ferramentas apontadas como não possuindo direta relação entre as teorias abordadas no artigo poderiam, por outras linhas de pensamento e análise ter suas naturezas fundidas e aplicadas tanto à Gestão do Conhecimento quanto à Comunicação Organizacional. Dessa forma, algo ainda importante a ser assinalado seria a sinalização das divergências entre os campos de Gestão do Conhecimento e Comunicação Organizacional; contudo, diante do levantamento bibliográfico realizado, das experiências obtidas por meio das entrevistas e da vivência com as áreas aqui mencionadas, as pontuais divergências podem ser ocultadas com o fim de diminuir as incertezas ou ambiguidades que poderiam ser geradas ao serem encontradas pelos estudiosos que terão contato com este trabalho. 


\section{Considerações Finais}

Entender os conceitos, analisar os tipos de conhecimento que uma organização possui, delimitar o campo de atuação das correntes apresentadas, embasando as teorias consolidadas, as informações apresentadas neste artigo e tomando por base o objetivo do trabalho que é de relacionar e analisar a as semelhanças e a aplicação prática da gestão do conhecimento a projetos de comunicação interna, concluem-se alguns aspectos.

O primeiro é que existem diversas ferramentas capazes de trazer melhorias aos processos e fluxos organizacionais que, quando bem utilizadas e geridas, trazem aumento de eficácia e alcance das ações planejadas e postas em práticas. Sem dúvida o preparo dos gestores de forma administrativa precisa ser observado. $E$ isso no sentido de fazer conhecidos todos os percursos burocráticos ou não, mas próprios da organização que, apropriados ao longo dos anos, possibilitaram a produção de fluxos e costumes organizacionais que funcionam e dão ritmo ao andamento das instituições. Um gestor mal informado ou alheio a esses processos pode facilmente incorrer no erro de ultrajar normas e condutas previamente estabelecidas pensadas anteriormente, justamente a fim de facilitar e propor caminhos pavimentados e conhecidos por onde as ações e os planos passam e se estabelecem no decorrer dos processos.

Uma segunda consideração a que se chega é a de que a necessidade de que se gerencie o conhecimento dentro das organizações parece ser real, comprovado pela fala da gestora Rejane Neves e pela experiência própria do autor, adquirida tanto no Conselho Nacional de Justiça, quanto na proveniente da experiência em outras instituições públicas e privadas. A necessidade de se difundir as informações, processos e especialmente o conhecimento por toda a organização é benéfico para todos os integrantes do ambiente composto nas instituições e também o desconhecimento generalizado pelas partes pares de uma organização, além de gerar dificuldades e entraves nos processos organizacionais, diminuem a eficiência de um ator público, que, preocupado em não repetir ou igualar formas, ferramentas e produtos do trabalho de seus colaboradores, deixa de ter disponibilidade para pensar a inovação, a gestão orgânica, fluida, criativa e sustentável; Fatores que gerariam ganho produtivo, intelectual e com resultados palpáveis. 
Observa-se, contudo que movimentações nesse sentido de promover a gestão e o compartilhamento do conhecimento já têm ocorrido, não só nas organizações públicas do Poder Judiciário Brasileiro, mas também e principalmente nas instituições privadas. $O$ antagonismo existente, principalmente em Brasília, entre as organizações de naturezas distintas precisa ceder espaço ao diálogo, à cooperação mútua e ao compartilhamento de ideias e boas práticas organizacionais de aplicabilidade viável em ambas as naturezas, pública e privada.

Os quadros que apresentam pontos de convergência entre as áreas da Gestão do Conhecimento e da Comunicação deixam à mostra tudo aquilo que pode e deve ser observado pelos gestores de comunicação quando da prática comunicacional, a fim de que vantagens obtidas nos dois campos possam ser aproveitadas e aplicadas de forma a gerar resultados mais duradouros, sólidos e de alcance notável.

Para concluir, por hora, a reflexão sobre o tema, havendo sobretudo a ciência de que a vastidão a ser explorada dentro do problema proposto é aberta para explorações futuras, tece-se a terceira consideração a ser feita. A aplicabilidade da gestão e do compartilhamento do conhecimento a projetos e divisões de comunicação nas/das organizações públicas existe e possui necessidade latente de execução para que haja significativas melhoras na comunicação dentro das organizações, difundindo o conhecimento adquirido e consagrado nas organizações, tornando-o acessível a todo o público interno e registrando-o para que não haja atritos ou gaps comunicacionais e de conhecimento para os que virão adiante dos presentes gestores.

Discutir a importância da relação do diálogo entre as teorias da Gestão do Conhecimento e da Comunicação Organizacional, que foi o objetivo deste trabalho, além de apresentar os pontos de contato entre ambas as teorias ainda precisa ser estudado e deve sempre ser mantido na mente daqueles que se interessam por promover mudanças e melhorias nos meios em que desenvolvem seus estudos e prática profissional. Desconsiderar tudo o que já existe e foi pensado e produzido no âmbito dos dois campos que este artigo suscita seria perder a oportunidade de promover grandes e benéficas transformações à sociedade, às organizações públicas e privadas e principalmente ao Brasil.

Esses futuros gestores de comunicação que se têm formado nas instituições de ensino devem permanecer atentos pois o universo apresenta constantes e diárias mudanças impossíveis de ser ignoradas, tanto na sociedade quanto nos processos 
de trabalho, comércio, indústria, pensamento e demais áreas, que, se devidamente ponderadas e analisadas, podem trazer ganhos à gestão da comunicação. A observância do desenvolvimento dos campos da gestão do conhecimento e da comunicação como um todo também é imprescindível e se faz bastante relevante para um trabalho de excelência por parte dos gestores. 


\section{Referências}

ANGELONI, Maria Terezinha (Org.) - Organizações do conhecimento: infraestrutura, pessoas e tecnologia. Ana Luísa Mulbert... [et. Al.]. - 2.ed. - São Paulo: Saraiva, 2008. BRASIL. Constituição (1988). Constituição da República Federativa do Brasil. Art. 37, com as alterações adotadas pela Emenda Constitucional nº 19, de 1998.

DAVENPORT, Thomas H.; PRUSAK, Laurence. 1954 - Conhecimento Empresarial. [Tradução de Lenke Peres] - Rio de Janeiro: Campus; São Paulo: Publifolha, 1999.

FORMIGA, Asdrubal Borges (Org.) - Muito além dos meios: comunicação organizacional: desafios e interfaces - David Renault ... [et al], (org.). Brasília: Editora Universidade de Brasília, 2014.

KUNSCH, Margarida M. Krohling. Relações públicas e modernidade: novos paradigmas na comunicação organizacional. São Paulo: Summus, 1997. [4. ed., ver., ampl. E atual. Em 2003]

KUNSCH, Margarida M. Krohling (Org.) - Comunicação organizacional: histórico, fundamentos e processos, volume 1 - São Paulo: Saraiva, 2009.

. - Comunicação organizacional: linguagem, gestão e perspectivas, volume 2 São Paulo: Saraiva, 2009.

MACIEL, Laura - Entrevista concedida em informação verbal. Brasília, 2017.

NASSAR, Paulo - O que é comunicação empresarial / Paulo Nassar e Rubens Figueiredo. São Paulo: Brasiliense, 1995.

NEVES, Rejane Maria Rodrigues - Entrevista concedida em informação verbal. Brasília, 2017.

Quem Somos. Conselho Nacional de Justiça. Disponível em:

<http://www.cnj.jus.br/sobre-o-cnj/quem-somos-visitas-e-contatos>. Acesso em: 28 mai. 2017.

TAKEUCHI, HIrotaka; NONAKA, Ikujiro. Hitotsubashi on Knowledge Management. Gestão do Conhecimento. [Tradução de: Ana Thorell]. São Paulo: Bookman, 2008. 


\section{Apêndice 1: Roteiro de Entrevista}

1) Qual o seu nome, profissão e local onde desempenha suas funções (especifique o nome da seção/departamento e instituição)?

2) Comente a importância da gestão do conhecimento em organizações públicas.

3) De que forma, a gestão e o compartilhamento de conhecimento podem contribuir para a melhoria de processos organizacionais?

4) Gestão do conhecimento e Comunicação Interna. O que esses dois conceitos têm em comum?

5) Na sua opinião, a teoria da gestão do conhecimento pode contribuir para projetos de comunicação interna em organizações públicas do poder judiciário? Como?

6) Qual o nível de conhecimento dos servidores do poder judiciário sobre a gestão do conhecimento e quanto ainda precisa ser trabalhado sobre o tema para que haja melhorias significativas nos processos internos das organizações? 